\title{
Allelopathic effects of humus forest soil of Hippophae rhamnoides, Caragana korshinskii and Amorpha fruticosa on medicinal plants
}

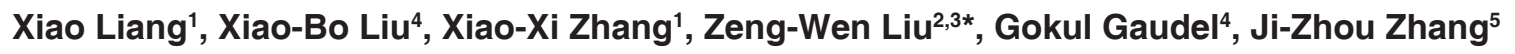 \\ ${ }^{1}$ Institute of Soil and Water Conservation, Northwest A\&F University, Yangling, Shaanxi712100, China, ${ }^{2}$ College of Natural Resources and \\ Environment, Northwest A\&F University, Yangling, Shaanxi, China, ${ }^{3}$ Key Laboratory of Plant Nutrition and the Agri-enviroment in Northwest \\ China, Ministry of Agriculture, Yangling, Shaanxi, China, ${ }^{4}$ College of Forestry, Northwest A\&F University, Yangling, Shaanxi712100, China, \\ ${ }^{5}$ Yang Ling Hi-tech Middle School, Yangling-712100, China
}

\section{A B S TR A C T}

\begin{abstract}
Allelopathic effect is an important problem in constructing tree-herb complex system. In order to choose medicinal plants which may be suitable for growth under the forests of the Loess Plateau, humus soil of 3 types of broad-leaved forests was collected as medium to conduct a pot-culture experiment. The allelopathic effects of the forest soil on the growth and physiology of 11 types of medicinal plant were studied. The results showed that Belamcanda chinensis, Arisaema heterophyllum, Saposhnikovia divaricata, Bupleurum chinense and Isatis tinctoria, which were significantly inhibited in humus soil of Hippophae rhamnoides forest should avoid to be planted in this forest; B. Chinense, Glycyrrhiza uralensis, B. Chinensis, Astragalus membranaceus and $A$. heterophyllu, which were significantly inhibited in the humus soil of Caragana korshinskii should avoid to be planted; in addition, A. heterophyllum, A. membranaceus, I. Tinctoria and $B$. Chinensis, which were significantly inhibited in the humus soil of Amorpha fruticosa should avoid to be planted.
\end{abstract}

Keywords: Allelopathic effects; Humus soil; Medicinal plants

\section{INTRODUCTION}

Hippophae rhamnoides, Caragana korshinskii and Amorpha fruticosa are three typical broad-leaved shrub species widely cultivated in the Loess Plateau because of the advantages of their resistance to drought and cold and their ability to improve the soil structure and fertility (Jia et al., 1996; Lu et al., 2013; Zhong et al., 2015). But, recently, along with the aging of the trees and soil degradation, many of the stands show slow growth as well as death. Liu et al. (2007a) defined this phenomenon as the theory of "soil polarization", and propose that forming complex ecosystem is an essential approach to alleviate soil polarization (Liu et al., 2007a; Li et al., 2013b). Tree-herb complex system had been recommended as a favorable form of complex system because of its ability to make full use of the land space, improve the land utilization and production benefit as well as become conducive to efficient unified economic, social and ecological benefits (Liu et al., 2007b).
Allelopathic effect is a serious problem, which cannot be ignored within tree-herb complex system. Previous studies had showed that leaching solutions from different parts of the H. rbamnoides can not only show remarkable allelopathic effect on germination of itself, but also have a significant impact on forests soil (Djurdjevic et al., 2004; Yuan et al., 2015); Various stem and leaf water extracts of A. fruticosa have inhibitory effect on soybean (Guo et al., 2010); moreover, Li et al. (2013b) stated that water extracts of $H$. rhamnoides, C. korshinskii and $A$. fruticosa leave show considerable inhibitory effect on Alfalfa. It is visible that allelopathy as a vehicle for interaction between species in ecological research area is very active, but never has gained sufficient attention in the tree-herb complex system in the Loess Plateau research.

The aforementioned researches offered foundation about how to take advantage of allelopathy among plants between species or within species to control and remove weeds,

\footnotetext{
${ }^{*}$ Corresponding author:

Zeng-Wen Liu, College of Natural Resources and Environment, Northwest A\&F University, Yangling, Key Laboratory of Plant Nutrition and the Agri-enviroment in Northwest China, Ministry of Agriculture, Yangling, Shaanxi712100, China. Mobile: 86 13689257764,

E-mail: zengwenliu2003@aliyun.com
} 
prevent and control crop pests and diseases (Meiners et al., 2014). However, most of these researches used water extract to deal with the receptor plants. In fact, which cannot completely simulate the actual situation in the field; because allelochemicals are firstly released into the environment through foliar leachates, root exudation, leaf litter or other-residue decomposition, or volatilization (Inderjit, 2005); and then affected by the microorganisms and nutrients in the soil, allelochemicals might be decomposed or resynthesis, the activities might be inhibited or simulated (Zhang et al., 2015). Considering the above facts and observation, it is better to use the soil as the source of allelochemicals and the aim of present study is to evaluate the allelopathic effect of humus soil of three typical shrubs deciduous tree species (Hippophae rhamnoides, Caragana korshinskii and Amorpha fruticosa) on seed germination and seedling growth of 11 species of local common medicinal plants.

\section{MATERIALS AND METHODS}

\section{Study sites}

Qiaoshan Forest Region (108 33'40" 109 $19^{\prime} 41^{\prime \prime}$ E, $\left.35^{\circ} 32^{\prime} 06^{\prime \prime} \sim 35^{\circ} 45^{\prime} 55^{\prime \prime} \mathrm{N}\right)$ is situated in the hilly-gully region of the Loess Plateau, Northern Shaanxi, China. It has a semi-arid and semi-humid climate: the average annual rainfall is $630.9 \mathrm{~mm}$, and the average annual temperature is $8.6^{\circ} \mathrm{C}$. Cinnamonic forest soil is the dominant soil type of this area. The elevation of the study area ranges from 1000 to $1500 \mathrm{~m}$.

\section{Humus soil collection and disposal}

In this study, the pure forests of $H$. rhamnoides, C. korshinskii and $A$. fruticosa with the same site conditions were chosen. In each forest, three sample plots with a size of $20 \mathrm{~m} \times 20 \mathrm{~m}$ were established and at the same time 5 quadrats $(1 \mathrm{~m} \times 1 \mathrm{~m})$ were settled within each sample plot. The soil of the humus layer $(0-10 \mathrm{~cm})$ within the quadrats was collected and thoroughly mixed after removing stones, large plant debris and visible roots. The fresh soil samples collected were sieved with a $5 \mathrm{~mm}$ wire mesh to reserve. With the same method, soil from tree-free waste grassland nearby the forests was sampled for the control testing (CK).

\section{Seeds preparation of the medicinal plants}

A total of eleven types of medicinal plant seeds, commonly planted in the study area were bought from local seed company in 2014, including Bupleurum chinense, Gyyyrrbiza uralensis, Astragalus membranaceus, Isatis tinctoria, Saposhnikovia divaricata, Platycodon grandiflorus, Polygala tenuifolia, Achyranthes bidentata, Angelica dahurica, Belamcanda chinensis and Arisaema beterophyllum. The uniform and plump seeds without any insect pests persecution were used for germination and pot cultivation tests (the germination rates of these seeds were over $85 \%$ confirmed by a pre-testing so that they were eligible for the following tests).

\section{Pot cultivation experiments}

The germination test was carried out under the rainproof device. One hundred of prepared seeds from each medicinal plant species were sowed in a pot (height: $15.5 \mathrm{~cm}$, diameter: $16.6 \mathrm{~cm}$ ) with each kind of $3 \mathrm{~kg}$ homogenized soil sample (the thickness of covering soil is 2.5 times of the diameter of the seeds), which was defined as a treatment and repeated for 3 times. After sowing, distilled water was added into pots to adjust the soil moisture to $60 \%$ of the field water holding capacity. Moreover, water was added every three days according to the water losses during the cultivation period, and all the pots were kept under the same environmental conditions (such as air temperature, light and soil humidity). During the germination and growth testing, in order to reduce intraspecific competition, seedlings were randomly pulled out to make sure that the remaining seedlings were kept uniformly distributed in the pot, and approximately 15 seedlings were remained for the final determinations of biomass and other physiological indicators.

\section{Determination of physicochemical indices}

Soil organic matter was determined using the potassium dichromate melting method: the detailed experiment process is as follows: first, put $0.5 \mathrm{~g}$ air-dried soil samples into $150 \mathrm{~mL}$ grinding mouth flasks and $0.5 \mathrm{~g}$ silica powder into another flask as blank calibration, then added $10 \mathrm{ml}$ potassium chromate-sulfuric acid solution of concentration of $0.4 \mathrm{~mol} \cdot \mathrm{L}^{-1}$ into each flask. Put an air condenser in each flask and place all flasks on the electric sand bath heater when temperature was stable on $200^{\circ} \mathrm{C}$. Secondly, start of timing when it came up the first drop at the bottom of an air condenser, and then removed flasks one by one from electric sand bath heater every five minutes. Thirdly, flushed condenser and make sure that the washing liquid fluid into original flask when all of the flasks were cooled. The total volume of the solution in a flask should be controlled at $60 \sim 80 \mathrm{~mL}$. Added three to five drops of phenanthroline indicator into flask, so as to titrate remaining dichromate with ferrous sulfate solution (the concentration of ferrous sulfate standard solution is $0.2 \mathrm{~mol} / \mathrm{L}$, it requires calibration before each titration), the initial color of solution is orange and it will turn into bluegreen at first, then came to the end when the color became reddish brown. Record the volume of ferrous sulfate from flask used in the titration and calculate the $\mathrm{C}$ content of soil samples. Available potassium $(\mathrm{K})$ was determined with $1.0 \mathrm{~mol} \cdot \mathrm{L}^{-1} \mathrm{NH}_{4} \mathrm{~A}_{\mathrm{c}}$ extraction by a flame photometer method; available phosphorus $(\mathrm{P})$ was determined with $0.5 \mathrm{~mol} \cdot \mathrm{L}^{-1}$ sodium hydrogen carbonate extraction by a 
UV-Vis spectrophotometer method; alkaline nitrogen (N) was determined with magnesium oxide by alkaline hydrolysis diffusion method (Bao, 2005; Griffiths et al., 2012). All treatments in this study were replicated 3 times. Control experiments were also conducted.

The germination indicators: The germination index was obtained by the following equation:

$G I=\sum(G t / D t)$

where GI is germination index, Gt is the number of germinated seeds and $D t$ is the corresponding germination time for $G t$.

The growth indicators: the root length and shoot height were measured. The biomass of each pot (shoot/root/ whole plants) was determined after being rinsed and oven dried at $65^{\circ} \mathrm{C}$ until the weight was constant.

The physiological indicators: Chlorophyll (Chl) content was determined by spectrophotometry method: $0.1 \mathrm{~g}$ leaf sample was ground with calcium carbonate and silica sand in $80 \%$ acetone in mortar and then the supernatant was filtered. The residues and filter paper were washed using acetone several times. All extraction solutions were transferred into a volumetric flask and the total solution was brought up to a volume of $25 \mathrm{ml}$. The final solution was analyzed with the spectrophotometer at 3 different wavelengths $(663 \mathrm{~nm}, 645 \mathrm{~nm}$, and $470 \mathrm{~nm})$; Malondialdehyde (MDA) content was determined using the thiobarbituric acid (TBA) method: $0.3 \mathrm{~g}$ leaf sample with $2 \mathrm{ml} \mathrm{10 \%} \mathrm{TBA} \mathrm{and} \mathrm{a} \mathrm{small} \mathrm{amount} \mathrm{of} \mathrm{quartz} \mathrm{sand}$ was ground to homogenate, plus $8 \mathrm{ml}$ TBA and grinding, centrifuge $3000 \mathrm{r} \cdot \mathrm{min}^{-1}$ for $15 \mathrm{~min}$, supernatant fluid extract for sample. Determination of chromogenic reaction and absorb centrifugal supernatant $2 \mathrm{ml}$ (plus $2 \mathrm{ml}$ distilled water for control), and then added $2 \mathrm{ml} 0.6 \%$ TBA solution, blending in a boiling water bath reaction $15 \mathrm{~min}$, rapid cooling and centrifugation again. Take that determination of supernatant fluid under the 532, 600 and $450 \mathrm{~nm}$ wavelength of dullness; Catalase (CAT) activity was determined using the titration method: first, $1.0 \mathrm{~g}$ leaf sample was ground with $0.2 \mathrm{~g}$ calcium carbonate and $2 \mathrm{ml}$ distilled water in mortar and grinding to homogenate which was diluted to $100 \mathrm{ml}$ into a volumetric flask. The mixture of $5 \mathrm{ml}$ of supernatant liquor and $5 \mathrm{ml}$ of hydrogen peroxid was incubated in a $20^{\circ} \mathrm{C}$ water bath for $5 \mathrm{~min}$, at the same time add $5 \mathrm{ml}$ sulfuric acid to steady all the undecomposed of hydrogen peroxide, then added $1 \mathrm{ml}$ potassium iodide, 3 drops of ammonium molybdate and 5 drops of starch indicator, at last titrated with a $0.01 \mathrm{~mol} \mathrm{~L}^{-1}$ sodium thiosulfate solution until the blue disappeared. (Gao, 2000; Chi, 2011; Zhang et al., 2015).

\section{Data analysis}

T-test was conducted using SPSS 20.0 for the data processing. The differences of indices were decided using t-test method between treatments and CK $(\alpha=0.05)$. The allelopathic response indices $R I$ were obtained by the following equation:

$R I=T / C-1$

(Where $T$ is the value obtained from treatments and $C$ is the value obtained from control testing $(\mathrm{CK})$. A positive $R I$ indicates the allelopathic promoting effect, and a negative one shows inhibition. The absolute value of $R I$ indicates the degree of effect.)

The integrated principal component analysis: The $R I$ valueswere submitted to SPSS 20.0 and analyzed by an integrated principal component analysis method. The $F$ obtained from this method was used to assess the comprehensive allelopathic effects of humus soil on medicinal plants. $F$ above zero indicated the allelopathic promoting effects, and the ones below showed inhibition.

\section{RESULTS}

The fertility of humus forest soil and wasteland (CK) Considering the soil feedback which can neutralizes potentially negative effects of allelochemicals, the nutrients of the three kinds of humus soils were tested contrasting to the wasteland as a pre-condition soil, followed by the response measure in which plant performance on these soils was measured. The aim was to distinguish the allelopathy from other effects such as changes in nutrient availability (Prati et al., 2004; Parepa et al., 2012). Nitrogen, phosphorus and potassium have been considered as key factors increasing the phytoplankton biomass (Elser et al., 2007). Relative to CK soil, soil samples from H. rhamnoides, C. korshinskii and $A$. fruticosa forests showed significantly higher content of organic matters, alkaline $\mathrm{N}$, available $\mathrm{P}$ and available $\mathrm{K}$ (Table 1). So, it is reasonable for us to think that the inhibition is mainly caused by the allelopathic effect.

Table 1: Soil fertility in humus forest soil of $H$. rhamnoides,

C. korshinskii, A. fruticosa and wasteland (CK)

\begin{tabular}{lcccc}
\hline $\begin{array}{l}\text { Source of } \\
\text { soil }\end{array}$ & $\begin{array}{c}\text { Organic } \\
\text { matter } \\
\left(\mathbf{g ~ k g}^{-1}\right)\end{array}$ & $\begin{array}{c}\text { Available N } \\
\left(\mathbf{m g ~ k g}^{-1}\right)\end{array}$ & $\begin{array}{c}\text { Available P } \\
\left(\mathbf{m g ~ k g}^{-1}\right)\end{array}$ & $\begin{array}{c}\text { Available K } \\
\left(\mathbf{m g ~ k g}^{-1}\right)\end{array}$ \\
\hline wasteland & 24.09 & 51.59 & 6.73 & 81.31 \\
H. rhamnoides & $31.09^{*}$ & $73.99^{*}$ & $13.18^{* *}$ & $179.79^{* *}$ \\
C. korshinskii & $31.87^{*}$ & $77.44^{*}$ & $10.25^{*}$ & $150.34^{\star *}$ \\
A. fruticosa & $36.69^{* *}$ & $73.51^{*}$ & $13.44^{* *}$ & $170.49^{* *}$ \\
\hline
\end{tabular}

${ }^{*}$ and ${ }^{* *}$ Indicate significant differences at 0.05 or 0.01 levels between soil nutrients of humus forest soil and waste grassland (CK) 


\section{Allelopathic effects on germination}

Germination Rate: in humus soil of $H$. rhamnoides pure forest: $S$. divaricata and $A$. heterophyllum showed a significant decrease by $30.2 \%$ and $35.7 \%$, respectively. In contrast, the humus soil from C. korshinskii pure forest could bring an obvious inhibitory effect on the medicinal plants: among them $S$. divaricata was mostly inhibited, with whose germination rate reduced by $62.8 \%$, followed by $B$. chinense with $60.0 \%$, meanwhile, the germination rate of A. heterophyllum, P. tenuifolia and B. chinensis also showed decreased by $42.9 \%, 40.0 \%$ and $37.0 \%$, respectively. Nevertheless, the humus soil of $A$. fruticosa pure forest almost had no obvious effect on any of medicinal plants (Table 2).

Germination Index: in humus soil of $H$. rhamnoides pure forest: $S$. divaricata and $B$. chinensis showed a significant decrease by $47.5 \%$ and $44.4 \%$, respectively. In the humus soil from C. korshinskii pure forest, the decreases in germination speed of $S$. divaricate, $P$. tenuifolia, B. chinense, B. chinensis and $A$. heterophyllum were $79.5 \%, 54.3 \%, 54.2 \%$, $53.0 \%$ and $47.0 \%$, respectively. No obvious effect was observed in the humus soil from $A$. fruticosa pure forest.

\section{Allelopathic effects on seedling growth}

Shoot height: H. rhamnoides humus soil had no obvious effect on the shoot height of all the medicinal plants except I. tinctoria whose shoot height was stimulated by $37.5 \%$ (Table 3). Both of the humus soils from C. korshinskii and $A$. fruticosa inhibited only $A$. membranaceus with reduction by $19.0 \%$ and $10.8 \%$, respectively.

Ground diameter: Inhibitory effects were not observed in both of the humus soil from $H$. rhamnoides and C. korshinskii. However, only the ground diameter of
B. chinensis was decreased by $35.0 \%$ in the humus soil from $A$. fruticosa.

Dry weight of root: B. chinensis was found to be obviously inhibited with the decrease of $79.3 \%$ in the humus soil of $H$. rhamnoides. Meanwhile, A. bidentata and B. chinense also showed different degree of decrease. Furthermore, B. chinense showed significant stimulatory effect in other two kinds of soil, the dry weight of root were reduced by $85.4 \%$ and $96.1 \%$, respectively.

Dry weight of shoot: In the humus soil of H. rhamnoides, A. heterophyllum was reduced by $73.0 \%$, and even B. chinense was completely blocked. In the humus soil of C. korshinskii, B. chinense was reduced by $85.9 \%$, followed by A. heterophyllum (65.7\%). On the contrary, B. chinense showed strong stimulatory effect in the humus soil of $A$. fruticosa.

Total dry weight: The highest reduction in the humus soil of H. rhamnoides was B. chinensis (52.7\%), followed by B. chinense $(41.6 \%)$ and $A$. beteropbyllum (37.5\%). The humus soil of C. korshinskii had no obvious effect on all the medicinal plants except $B$. chinense and $A$. heterophyllum. The reductions were $86.1 \%$ and $24.9 \%$, respectively. Nevertheless, no effect was found in the humus soil of $A$. fruticosa.

\section{Allelopathic effects on physiological properties}

Chlorophyll content: Three types of humus soil had varying effect on Chl content (Table 4). Humus soil of H. rhamnoides decreased the Chl content of I. tinctoria and A. dahurica by $30.5 \%$ and $25.0 \%$, respectively. In the humus soil of C. korshinskii only the Chl content of $A$. daburica was reduced by $16.6 \%$. Moreover, the humus soil of $A$. fruticosa showed significant effect on I. tinctoria, G. uralensis,

Table 2: Seed germination indices of medicinal plants potted with forest humus soil of $H$. hamnoides, $C$. korshinskii and A. fruticosa

\begin{tabular}{lllllccccccccc}
\hline Index & Soil & & B.ce. & G.u. & A.m. & I.t. & S.d. & P.g. & P.t. & A.b. & A.d. & B.cs. & A.h. \\
\hline GR (\%) & Wasteland & CK & 15.000 & 31.330 & 46.000 & 69.670 & 43.330 & 43.330 & 20.000 & 35.670 & 29.000 & 27.000 & 27.670 \\
& H.r. & $T$ & 11.333 & 36.000 & 48.000 & 74.667 & $30.000^{*}$ & 45.000 & 26.333 & 56.660 & 30.667 & 22.000 & $17.667^{*}$ \\
& & $R I$ & -0.267 & 0.161 & 0.043 & 0.071 & -0.302 & 0.047 & 0.300 & 0.583 & 0.069 & -0.185 & -0.357 \\
& C.k. & $T$ & $6.333^{*}$ & 25.000 & 57.667 & 62.333 & $16.330^{*}$ & 45.333 & $12.002^{*}$ & 58.330 & 27.333 & $17.000^{*}$ & $16.333^{*}$ \\
& & RI & -0.600 & -0.194 & 0.261 & -0.114 & -0.628 & 0.047 & -0.400 & 0.611 & -0.069 & -0.370 & -0.429 \\
& A.f. & $T$ & 17.667 & 37.333 & 44.333 & 65.667 & 45.000 & 46.667 & 25.667 & 49.000 & 33.000 & 33.667 & 25.000 \\
& & $R I$ & 0.200 & 0.194 & -0.043 & -0.043 & 0.047 & 0.093 & 0.280 & 0.361 & 0.138 & 0.259 & -0.107 \\
GI & Wasteland & CK & 4.250 & 29.680 & 22.600 & 58.800 & 11.410 & 7.950 & 5.340 & 19.510 & 4.910 & 5.950 & 11.070 \\
& H.r. & $T$ & 3.108 & 28.481 & 25.265 & 52.202 & $5.990^{*}$ & 10.313 & 6.844 & 24.655 & 6.663 & $3.303^{*}$ & 7.785 \\
& & $R I$ & -0.270 & -0.041 & 0.118 & -0.112 & -0.475 & 0.298 & 0.282 & 0.264 & 0.358 & -0.444 & -0.297 \\
& C.k. & $T$ & $1.952^{*}$ & 25.481 & 17.723 & 60.207 & $2.340^{*}$ & 10.024 & $2.482^{*}$ & 23.382 & 5.640 & $2.781^{*}$ & $5.882^{*}$ \\
& & RI & -0.542 & -0.141 & -0.216 & 0.024 & -0.795 & 0.261 & -0.543 & 0.198 & 0.149 & -0.530 & -0.470 \\
& A.f. & $T$ & 5.405 & 34.405 & 25.109 & 53.669 & 10.535 & 9.452 & 7.684 & 26.956 & 4.886 & 7.031 & 10.122 \\
& & $R I$ & 0.270 & 0.159 & 0.111 & -0.087 & -0.077 & 0.189 & 0.440 & 0.381 & 0.004 & 0.182 & -0.086 \\
\hline
\end{tabular}

*Indicated significant differences between experimental value and control value $(\mathrm{P}<0.05)$. B.ce.: Bupleurum chinense, G.u.: Glycyrrhiza uralensis, A.m.: Astragalus membranaceus, I.t.: Isatis tinctoria, S.d.: Saposhnikovia divaricata, P.g.: Platycodon grandiflorus, P.t.: Polygala tenuifolia, A.b.: Achyranthes bidentata, A.d.: Angelica dahurica, B.cs.: Belamcanda chinensis, A.h.: Arisaema heterophyllum, GR: Germination rate, Gl: Germination index 
Table 3: Seedling growth indices of medicinal plants potted with forest humus soil of $H$. rhamnoides, $C$. korshinskii and A. fruticosa

\begin{tabular}{|c|c|c|c|c|c|c|c|c|c|c|c|c|c|}
\hline Index & Soil & & B.ce. & G.u. & A.m. & l.t. & S.d. & P.g. & P.t. & A.b. & A.d. & B.cs. & A.h. \\
\hline \multirow[t]{7}{*}{ Shoot height $(\mathrm{cm})$} & Wasteland & CK & 18.600 & 18.733 & 31.500 & 19.300 & 14.200 & 6.200 & 14.800 & 10.467 & 7.900 & 20.533 & 9.033 \\
\hline & H.r. & $T$ & 20.100 & 19.164 & 30.753 & $12.068^{*}$ & 17.700 & 10.200 & 18.000 & 9.876 & 15.633 & 28.067 & 8.800 \\
\hline & & $R I$ & 0.081 & 0.023 & -0.024 & -0.375 & 0.246 & 0.645 & 0.216 & -0.056 & 0.979 & 0.367 & -0.026 \\
\hline & C.k. & $T$ & 16.200 & 17.114 & $25.513^{*}$ & 18.354 & 18.200 & 16.800 & 12.963 & 17.800 & 12.300 & 27.333 & 14.900 \\
\hline & & $R I$ & -0.129 & -0.086 & -0.190 & -0.049 & 0.282 & 1.710 & 0.239 & 0.203 & 0.557 & 0.331 & 0.649 \\
\hline & A.f. & $T$ & 19.600 & 18.457 & $28.100^{*}$ & 18.668 & 25.900 & 20.600 & 18.200 & 13.700 & 15.400 & 29.500 & 14.600 \\
\hline & & $R I$ & 0.054 & -0.015 & -0.108 & -0.033 & 0.824 & 2.323 & 0.230 & 0.309 & 0.949 & 0.437 & 0.616 \\
\hline \multirow[t]{7}{*}{ Ground diameter (mm) } & Wasteland & CK & 0.104 & 0.057 & 0.078 & 0.092 & 0.128 & 0.058 & 0.144 & 0.144 & 0.244 & 0.024 & 0.220 \\
\hline & H.r. & $T$ & 0.188 & 0.074 & 0.081 & 0.107 & 0.244 & 0.112 & 0.192 & 0.130 & 0.357 & 0.013 & 0.232 \\
\hline & & $R I$ & 0.808 & 0.304 & 0.038 & 0.158 & 0.906 & 0.931 & 0.333 & -0.098 & 0.464 & 0.458 & 0.055 \\
\hline & C.k. & $T$ & 0.120 & 0.055 & 0.067 & 0.103 & 0.160 & 0.118 & 0.143 & 0.184 & 0.342 & 0.017 & 0.262 \\
\hline & & $R I$ & 0.154 & -0.032 & -0.145 & 0.124 & 0.250 & 1.034 & 0.004 & 0.278 & 0.402 & -0.150 & 0.191 \\
\hline & A.f. & $T$ & 0.132 & 0.067 & 0.073 & 0.117 & 0.280 & 0.158 & 0.134 & 0.198 & 0.298 & $0.013^{*}$ & 0.293 \\
\hline & & $R I$ & 0.269 & 0.175 & -0.064 & 0.267 & 1.188 & 1.724 & -0.069 & 0.373 & 0.221 & -0.350 & 0.330 \\
\hline \multirow[t]{7}{*}{ Root dry weight $\left(\mathrm{g} \cdot\right.$ plot $\left.^{-1}\right)$} & Wasteland & CK & 0.960 & 0.060 & 0.030 & 0.020 & 0.112 & 0.082 & 0.047 & 0.043 & 0.014 & 0.343 & 0.310 \\
\hline & H.r. & $T$ & 0.590 & 0.115 & 0.105 & 0.026 & 0.119 & 0.178 & 0.061 & 0.026 & 0.061 & $0.071^{*}$ & 0.282 \\
\hline & & $R I$ & -0.385 & 0.917 & 2.500 & 0.300 & 0.062 & 1.171 & 0.298 & -0.395 & 3.357 & -0.793 & -0.090 \\
\hline & C.k. & $T$ & $0.140^{*}$ & 0.275 & 0.264 & 0.071 & 0.090 & 0.232 & 0.056 & & 0.095 & 0.333 & 0.334 \\
\hline & & $R I$ & -0.854 & 3.583 & 7.800 & 2.550 & -0.196 & 1.829 & 0.302 & 1.298 & 5.786 & -0.029 & 0.077 \\
\hline & A.f. & $T$ & $0.037^{*}$ & 0.117 & 0.740 & 0.037 & 0.206 & 0.334 & 0.079 & 0.141 & 0.112 & 0.386 & 0.608 \\
\hline & & $R I$ & -0.961 & 0.950 & 23.667 & 0.850 & 0.839 & 3.073 & 0.681 & 2.279 & 7.000 & 0.125 & 0.961 \\
\hline \multirow[t]{7}{*}{ Shoot dry weight $\left(\mathrm{g} \cdot\right.$ plot $\left.^{-1}\right)$} & Wasteland & CK & 0.057 & 0.092 & 0.090 & 0.230 & 0.069 & 0.079 & 0.087 & 0.085 & 0.033 & 0.175 & 0.248 \\
\hline & H.r. & $T$ & $0.000^{*}$ & 0.104 & 0.150 & 0.200 & 0.190 & 0.132 & 0.122 & 0.089 & 0.111 & 0.174 & $0.067^{*}$ \\
\hline & & $R I$ & -1.000 & 0.130 & 0.667 & -0.130 & 1.754 & 0.671 & 0.402 & 0.047 & 2.364 & -0.006 & -0.730 \\
\hline & C.k. & $T$ & $0.008^{*}$ & 0.186 & 0.097 & 0.210 & 0.224 & 0.263 & 0.276 & 0.285 & 0.070 & 0.236 & $0.085^{*}$ \\
\hline & & $R I$ & -0.859 & 1.022 & 0.078 & -0.087 & 2.246 & 2.329 & 2.247 & 2.276 & 1.121 & 0.349 & -0.657 \\
\hline & A.f. & $T$ & $1.530^{*}$ & 0.138 & 0.247 & 0.420 & 0.469 & 0.382 & 0.115 & 0.476 & 0.121 & 0.173 & 0.116 \\
\hline & & $R I$ & 29.600 & 0.500 & 1.744 & 0.826 & 5.797 & 3.835 & 0.322 & 4.600 & 2.667 & -0.011 & -0.532 \\
\hline \multirow[t]{7}{*}{ Total dry weight $\left(\mathrm{g} \cdot\right.$ plot $\left.^{-1}\right)$} & Wasteland & $\mathrm{CK}$ & 0.096 & 0.152 & 0.120 & 0.230 & 0.181 & 0.161 & 0.134 & 0.128 & 0.047 & 0.518 & 0.558 \\
\hline & H.r. & $T$ & $0.590^{*}$ & 0.219 & 0.255 & 0.226 & 0.309 & 0.310 & 0.183 & 0.115 & 0.172 & $0.245^{*}$ & $0.349^{*}$ \\
\hline & & $R I$ & -0.416 & 0.441 & 1.125 & -0.096 & 0.707 & 0.925 & 0.366 & -0.102 & 2.660 & -0.527 & -0.375 \\
\hline & C.k. & $T$ & $0.140^{*}$ & 0.461 & 0.361 & 0.281 & 0.314 & 0.495 & 0.332 & 0.393 & 0.165 & 0.569 & $0.419^{*}$ \\
\hline & & $R I$ & -0.861 & 2.033 & 2.008 & 0.124 & 0.735 & 2.075 & 1.594 & 1.933 & 2.511 & 0.098 & -0.249 \\
\hline & A.f. & $T$ & 1.530 & 0.255 & 0.987 & 0.457 & 0.675 & 0.716 & 0.194 & 0.617 & 0.233 & 0.559 & 0.724 \\
\hline & & $R I$ & 0.515 & 0.678 & 7.225 & 0.828 & 2.729 & 3.447 & 0.448 & 3.820 & 3.957 & 0.079 & 0.297 \\
\hline
\end{tabular}

B.ce.: Bupleurum chinense, G.u.: Glycyrrhiza uralensis, A.m.: Astragalus membranaceus, I.t.: Isatis tinctoria, S.d.: Saposhnikovia divaricata, P.g.: Platycodon grandiflorus, P.t.: Polygala tenuifolia, A.b.: Achyranthes bidentata, A.d.: Angelica dahurica, B.cs.: Belamcanda chinensis, A.h.: Arisaema heterophyllum, GR: Germination rate, Gl: Germination index

A. daburica and B. chinense. The reductions of Chl contents were $35.7 \%, 27.6 \%, 26.7$ and $18.8 \%$, respectively.

Malondialdehyde content: the MDA content of B. chinense, P. tenuifolia, A. heterophyllum and G. uralensis were increased by $282.1 \%, 246.3 \%, 65.7 \%$ and $63.4 \%$ in the humus soil of H. rhamnoides. The MDA contents of B. chinense, G. uralensis and $A$. membranaceus were increased by $126.3 \%, 74.2 \%$ and $43.0 \%$ in the humus soil of C. korshinskii. In addition, in the humus soil of $A$. fruticosa, the MDA contents of B. chinense, P. tenuifolia, $A$. bidentata and $A$. daburica were increased by $182.3 \%, 121.5 \%, 55.2 \%$ and $52.6 \%$, respectively.

Catalase activity: the CAT activities of B. chinensis, A. daburica, G. uralensis and B. chinense were decreased by $76.3 \%, 74.1 \%, 68.8 \%$ and $33.6 \%$ in the humus soil of
H. rhamnoides. The CAT activities of A. daburica, G. uralensis and B. chinense were decreased by $68.2 \%, 55.9 \%$ and $41.0 \%$ in the humus soil of C. korshinskii. The CAT activities of $A$. dahurica, B. chinensis and B. chinense were decreased by $50.9 \%, 47.4 \%$ and $46.3 \%$ in the humus soil of $A$. fruticosa.

\section{The integrated allelopathic effects on medicinal plants}

To assess the integrated allelopathic effects on medicinal plants, the obtained $R I$ values of germination rate, germination index, shoot height, ground diameter, shoot dry weight, root dry weight, total dry weight, contents of Chl and MDA, and activities of CAT were analysed by SPSS 20.0 for principal component analysis (the higher content of MDA indicated the inhibitory effects, thus the $R I$ values of MDA were converted into reciprocals). The obtained models of comprehensive principal components 
Table 4: Seedling physiological indices of medicinal plants potted with forest humus soil of $H$. rhamnoides, $C$. korshinskii and A. fruticosa

\begin{tabular}{|c|c|c|c|c|c|c|c|c|c|c|c|c|c|}
\hline Index & Soil & & B.ce. & G.u. & A.m. & I.t. & S.d. & P.g. & P.t. & A.b. & A.d. & B.cs. & A.h. \\
\hline \multirow[t]{7}{*}{ Chl content $\left(\mathrm{mg} \cdot \mathrm{g}^{-1}\right)$} & Wasteland & $\mathrm{CK}$ & 3.329 & 1.872 & 0.652 & 1.421 & 1.006 & 1.035 & 1.336 & 1.090 & 1.900 & 1.449 & 1.664 \\
\hline & H.r. & $T$ & 4.245 & 2.101 & 1.316 & $0.988^{*}$ & 1.481 & 1.696 & 1.153 & 1.070 & $1.425^{\star}$ & 1.238 & 2.135 \\
\hline & & $R I$ & 0.275 & 0.122 & 1.018 & -0.305 & 0.472 & 0.638 & -0.137 & -0.018 & -0.250 & -0.146 & 0.283 \\
\hline & C.k. & $T$ & 3.818 & 1.667 & 1.572 & 1.929 & 1.260 & 1.660 & 1.202 & 1.516 & $1.585^{\star}$ & 1.416 & 1.954 \\
\hline & & $R I$ & 0.147 & -0.110 & 1.409 & 0.357 & 0.252 & 0.603 & -0.100 & 0.391 & -0.166 & -0.022 & 0.174 \\
\hline & A.f. & $T$ & $2.703^{*}$ & $1.356^{*}$ & 1.573 & $0.914^{*}$ & 1.551 & 1.255 & 1.321 & 0.943 & $1.392^{*}$ & 1.739 & 1.852 \\
\hline & & $R I$ & -0.188 & -0.276 & 1.412 & -0.357 & 0.541 & 0.212 & -0.011 & -0.135 & -0.267 & 0.200 & 0.113 \\
\hline \multirow[t]{7}{*}{ MDA content $\left(\mathrm{mmol} \cdot \mathrm{g}^{-1} \mathrm{FM}\right)$} & Wasteland & CK & 6.366 & 1.732 & 2.788 & 2.209 & 1.639 & 0.710 & 3.550 & 1.908 & 12.840 & 1.064 & 0.610 \\
\hline & H.r. & $T$ & $24.328^{*}$ & $2.830^{*}$ & 3.559 & 1.220 & 2.029 & 0.127 & $12.292^{*}$ & 2.180 & 7.803 & 1.027 & $1.011^{*}$ \\
\hline & & $R I$ & 2.821 & 0.634 & 0.277 & -0.448 & 0.238 & 0.202 & 2.463 & 0.143 & -0.392 & -0.035 & 0.657 \\
\hline & C.k. & $T$ & $14.404^{*}$ & $3.017^{*}$ & $3.987^{*}$ & 1.456 & 2.136 & 0.203 & 4.507 & 1.556 & 16.514 & 1.354 & 0.593 \\
\hline & & $R I$ & 1.263 & 0.742 & 0.430 & -0.341 & 0.303 & -0.345 & 0.270 & -0.185 & 0.286 & 0.273 & -0.029 \\
\hline & A.f. & $T$ & $17.973^{*}$ & 2.566 & 3.365 & 1.105 & 2.275 & 0.194 & $7.862^{*}$ & $2.962^{*}$ & $19.593^{*}$ & 0.786 & 0.505 \\
\hline & & $R I$ & 1.823 & 0.481 & 0.207 & -0.500 & 0.388 & 0.047 & 1.215 & 0.552 & 0.526 & -0.261 & -0.173 \\
\hline \multirow[t]{7}{*}{ CAT activity (mg g$\left.{ }^{-1} \mathrm{~min}^{-1}\right)$} & Wasteland & CK & 3.893 & 2.831 & 1.934 & 1.658 & 1.327 & 2.176 & 1.794 & 1.800 & 6.333 & 1.828 & 1.989 \\
\hline & H.r. & $T$ & 2.584 & $0.882^{*}$ & 2.678 & 2.253 & 0.731 & 2.142 & 13.541 & 2.445 & $1.641^{*}$ & $0.434^{*}$ & 3.137 \\
\hline & & $R I$ & -0.336 & -0.688 & 0.384 & 0.359 & -0.449 & -0.016 & 6.550 & 0.353 & -0.741 & -0.763 & 0.577 \\
\hline & C.k. & $T$ & $2.295^{\star}$ & $1.250^{*}$ & 1.598 & 2.074 & 1.683 & 2.474 & 10.617 & 1.898 & $2.015^{\star}$ & 3.162 & 2.448 \\
\hline & & $R I$ & -0.410 & -0.559 & -0.174 & 0.251 & 0.268 & 0.137 & 4.919 & 0.050 & -0.682 & 0.730 & 0.231 \\
\hline & A.f. & $T$ & $2.091^{*}$ & 2.423 & 1.360 & 1.284 & 1.675 & 1.411 & 1.428 & 2.137 & $3.111^{*}$ & $0.960^{*}$ & 5.848 \\
\hline & & $R I$ & -0.463 & -0.144 & -0.297 & -0.226 & 0.262 & -0.352 & -0.204 & 0.183 & -0.509 & -0.474 & 1.940 \\
\hline
\end{tabular}

B.ce.: Bupleurum chinense, G.u.: Glycyrrhiza uralensis, A.m.: Astragalus membranaceus, I.t.: Isatis tinctoria, S.d.: Saposhnikovia divaricata, P.g.: Platycodon grandiflorus, P.t.: Polygala tenuifolia, A.b.: Achyranthes bidentata, A.d.: Angelica dahurica, B.cs.: Belamcanda chinensis, A.h.: Arisaema heterophyllum, GR: Germination rate, Gl: Germination index

value $(F)$ were presented in equations (3) and (4) and the $F$ values were given in Fig. 1:

$$
\begin{aligned}
& F_{H . \text { rhammoides. }}=0.396 F_{1}+0.271 F_{2}+0.185 F_{3}+0.148 F_{4} \\
& F_{C . \text { karsshinskii. }}=0.493 F_{1}+0.345 F_{2}+0.162 F_{3} \\
& F_{\text {A.fruticosa. }}=0.347 F_{1}+0.283 F_{2}+0.213 F_{3}+0.157 F_{4}
\end{aligned}
$$

The results revealed that humus soil from H. rhamnoides pure forest showed the most obvious inhibitory effects on $B$. chinensis and $A$. bidentata, followed by B. chinense, A. heterophyllum, I. tinctoria, $S$. divaricata and $P$. grandifloras. Humus soil from C. korshinskii pure forest showed the most obvious inhibitory effects on $B$. chinense, followed by G. uralensis, A. membranaceus, B. chinensis, A. heterophyllum and $S$. divaricata. Humus soil from $A$. fruticosa pure forest showed the most obvious inhibitory effects on A. membranaceus, followed by A. heterophyllum, I. tinctoria, B. chinensis and G. uralensis.

\section{DISCUSSION}

The main object of our study was to test the role of allelopathic effect in tree-herb complex system. Surprisingly, we found both positive and negative effects on medicinal plants performance. Allelopathy is defined as neighbor suppression by releasing toxic biochemicals which

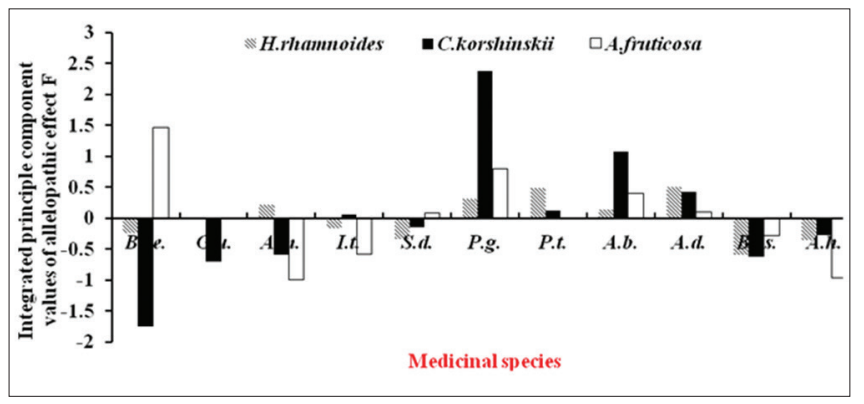

Fig 1. Comprehensive principal components value of allelopathic effects of humus forest soil of $H$. rhamnoides, $C$. korshinskii and A. fruticosa on medicinal plants. B.ce.: Bupleurum chinense, G.u.: Glycyrrhiza uralensis, A.m.: Astragalus membranaceus, I.t.: Isatis tinctoria, S.d.: Saposhnikovia divaricata, P.g.: Platycodon grandiflorus, P.t.: Polygala tenuifolia, A.b.: Achyranthes bidentata, A.d.-Angelica dahurica, B.cs.: Belamcanda chinensis, A.h.: Arisaema heterophyllum.

may affect other species directly or indirectly via changes to the soil microbial community and the physicochemical property and nutrient status (Inderjit et al., 2011; Fabbro et al., 2014).

Our results indicated that both of the humus soil from H. rhamnoides and C. korshinskii pure forests significantly inhibited the seeds germination of $S$. divaricata, $B$. chinensis and $A$. heterophyllum. However, the humus soil from $A$. fruticosa did not inhibit the germination of aforementioned medicinal plants. The possible reason is that allelochemicals with selectivity and specificities 
which come from same kind of humus soil can effect seed germination of different medicinal materials and from different kinds of humus soil can effect seed germination of same medicinal material (Yang et al., 2005; Ma et al., 2006), which was supported by the findings of Guo et al. (2010) who stated that the leaf water extracts from A. fruticosa show allelopathic inhibition effect on the seed germination and seedling growth of soybean and fababean. And also allelochemicals affected seed cell membrane permeability, cell division and differentiation, respiration, protein synthesis, gene expression, and hormone synthesis and equilibrium (Brunel-Muguet et al., 2015). Nevertheless, in this study, the humus soil from C. korshinskizinhibited the seed germination of Glycyrrbiza uralensis, which is not in line with the findings of Sun et al. (2008), who reported that C. korshinskii roots leaf water extract caused significantly inhibition on the seed germination of Glycyrrbiza uralensis. Based on these differences it shows that the allelochemicals obtained from different sources (living leave water extract/ soil) were different, because allelochemicals may be decomposed or transformed in the soil, which resulted in altering the activities or structure of allelochemicals (Zhang et al., 2015).

There are some similarities and differences between C. korshinskii and $A$. fruticosa, for instance, the root dry weigh of $B$. chinense was decreased by $85.4 \%$ and $96.1 \%$ in both soils. This is similar with the findings of several previous studies, in which they showed that certain phenolic acids which were identified in plant root exudates can be active allelochemicals and can cause detrimental effects on the growth of their neighbor plants by changing the distribution of the hormone or water balance (Hao et al., 2010; Zhang et al., 2010; Zhou et al., 2012). However, differences are that humus soil of C. korshinskii increased the shoot dry weigh of $B$. chinense by $85.9 \%$, which contributed to the total dry weigh; but soil of $A$. fruticosa performanced inversely. This may be caused by rhizodeposition (microbial metabolism can determine the duration and magnitude of allelopathic interactions attributed to phytotoxic phenolic acids present in soil, Dennis et al., 2010; Cipollini et al., 2012). Certain microbes distributed around $A$. fruticosa roots might degrade the allelochemicals or autotoxins (Kaur et al., 2009; Weidenhamer et al., 2013), and changeover the effects of allelochemicals. Besides, only the shoot height of I. tinctoria decreased in humus soil of $H$. rhamnoides. A reasonable explanation is probable that allelochemicals such as isobutyric acid, butyric acid, or isovaleric acid can suppress the hydrolysis of protein, thus I. tinctoria grew smaller than others, which was supported by the finding of Song et al. (2006).

The allelopathic effects on physiological properties are also variable. In this study, the results displayed that CAT activity of certain medicinal plants (G. uralensis, B. chinensis, $B$. chinense) experienced different degree of inhibition in different humus soils, which may have the MDA content of $B$. chinense to increase sharply in all three kinds of soils. The reason may be that the enzyme activity was inhibited by the free radicals procured in the cell (Blackhall et al., 2004), or the enzyme synthesis of CAT has been affected by salicylic acid, which can produce too much reactive oxygen species (ROS) (Chen et al., 2008). CAT, as a member of ROS enzymatic removing system, which can reduce the $\mathrm{H}_{2} \mathrm{O}_{2}$ to non-poisonous $\mathrm{O}_{2}$ and $\mathrm{H}_{2} \mathrm{O}$ in order to protect the cell membrane, it has the potential to defense against produced hydrogen peroxide as a part of the macromolecules breakdown (Haddad et al., 2004). Thus, once the cell membrane has been peroxidized by the strong oxidation effect of the ROS, MDA, as one of the final products of lipid peroxidation will be increased, which is in accordance to the conclusion from Li et al. (2013a).

Results from our study showed that the Chl content of most medicinal plants increased, which may be caused by the increase in $\mathrm{N}$ availability (Trouwborst et al., 2011) according to Table 1 . However, Chl content of $A$. daburica from all three kinds of humus soil was decreased. This significant difference might be explained as a mechanism of the photosynthesis among this tree-herb complex system: allelochemicals can affect plant respiration by weakening the ability to absorb oxygen; which influenced the photosynthesis resulting in the decrease of chlorophyll content (Xie et al., 2014; John et al., 2015). Meanwhile, it is worth mentioning that alkaloids have received comparatively less attention from allelopathy researchers than other compounds (Lovett et al., 1985; Hartmann, 2004), but common alkaloids have been reported to affect DNA synthesis, respiration, and electron transport, which can also contribute to the $\mathrm{Chl}$ reducing.

\section{CONCLUSION}

Humus soil from $H$. rhamnoides forest showed integrated allelopathic inhibitory effects on B. chinense, A. heterophyllum, I. tinctoria and B. chinensis, these medicinal plants should avoid being planted in $H$. rhamnoides forest. Likewise, $B$. chinense, G. uralensis and A. membranaceus, which showed integrated allelopathic inhibitory effects, should avoid being planted in humus soil of C. korshinskii forest. Besides, A. membranaceus, A heterophyllum and I tinctoria should avoid being planted in humus soil of $A$. fruticosa forest.

\section{ACKNOWLEDGEMENTS}

This work was supported by the National Natural Science Foundation of China (31070630) and the project of Key 
Laboratory of Plant Nutrition and the Agri-environment in Northwest China, Ministry of Agriculture. We appreciate Gokul Gaudel and Upendra Raj Bhattarai for critical reading and English language editing of the manuscript and their helpful comments on this manuscript, and also we thank Yuanhao Bing, Bochao Zhu, Nhu Trung Luc for the indoor experiments.

\section{Authors' contribution}

XL participated in experiments, analyzed the data and also drafted the manuscript; ZWL designed the research plan; $\mathrm{XBL}$ and JZZ made a major contribution to conducting experiments; XXZ revised the manuscript. Without their support it is impossible to perform the research. All authors read and approved the final manuscript.

\section{REFERENCES}

Bao, S. D. 2005. Methods of Soil Agro-Chemistry Analysis [M]. China Agriculture Press, Beijing.

Brunel-Muguet, S., P. D’Hooghe, M. P. Bataillé, C. Larré, T. H. Kim, J. Trouverie, J. C. Avice, P. Etienne and C. Dürr. 2015. Heat stress during seed filling interferes with sulfur restriction on grain composition and seed germination in oilseed rape (Brassica napus L.). Front. Plant Sci. 6: 213. DOI: 10.3389/ fpls.2015.00213.

Chen, F. Q., N. N. Song, G. H. Chen and J. Z. Wang. 2015. Effects of exotic species Larix kaempferi on diversity and activity of soil microorganisms in Dalaoling National Forest Park. Ecol. Processes. 4: 1-8.

Chen, J. F., G. N. Wang and S. M. Cheng. 2008. Progress about catalase function in plant stress reactions. Acta Bot. Boreal Occidental. Sin. 28: 188-193.

Chi, M. 2011. Allelopathy of different agroforestry systems in the Weibei Area of Shaanxi. Master Dissertation, Northwest A\&F University, Yangling, China.

Cipollini, D., C. M. Rigsby and E. K. Barto. 2012. Microbes as targets and mediators of allelopathy in plants. J. Chem. Ecol. 38: 714-727.

Dennis, P. G., A. J. Miller and P. R. Hirsch. 2010. Are root exudates more important than other sources of rhizodeposits in structuring rhizosphere bacterial communities? FEMS Microbiol. Ecol. 72: 313-327.

Djurdjevic, L., A. Dinic, P. Pavlovic, M. Mitrovic, B. Karadzic and V. Tesevic. 2004. Allelopathic potential of Allium ursinum L. Biochem. Syst. Ecol. 32: 533-544.

Elser, J. J., M. E. S. Bracken, E. E. Cleland, D. S. Gruner, W. S. Harpole and H. Hillebrand. 2007. Global analysis of nitrogen and phosphorus limitation of primary producers in freshwater, marine and terrestrial ecosystems. Ecol. Lett. 10: 1135-1142.

Fabbro, C. D., S. Gusewell and D. Prati. 2014. Allelopathic effects of three plant invaders on germination of native species: A field study. Biol. Invasions. 5: 1035-1042.

Gao, J. F. 2000. Experimental Guidance for Plant Physiology. Higher Education Press, Beijing.

Guo, Z. L., C. F. Cai and M. J. Zheng. 2010. Allelopathic effect of leaf water extracts from Amorpha fruticosa on germination and seedling growth of soybean and fababean. J. Huazhong Agric. Univ. 29: 452-456.
Griffiths, B. S., A. Spilles and M. Bonkowski. 2012. C: N: P stoichiometry and nutrient limitation of the soil microbial biomass in a grazed grassland site under experimental $\mathrm{P}$ limitation or excess. Ecol. Processes. 1: 1-11.

Haddad, R., K. Morris and W. V. Buchanan. 2004. Expression analysis of genes related to oxidative protection during senescence in Brassica napus. Iran. J. Biotechnol. 2: 269-277.

Hao, W. Y., L. X. Ren, W. Ran and Q. R. Shen. 2010. Allelopathic effects of root exudates from watermelon and rice plants on Fusarium oxysporum f. sp. niveum. Plant Soil. 336: 485-497.

Hartmann, T. 2004. Plant-derived secondary metabolites as defensive chemicals in herbivorous insects: A case study in chemical ecology. Planta. 219: 1-4.

Inderjit, D., A. Wardle, R. Karban and R. M. Callaway. 2011. The ecosystem and evolutionary contexts of allelopathy. Trends Ecol. Evol. 26: 655-662.

Inderjit. 2005. Soil microorganisms: An important determinant of allelopathic activity. Plant. Soil. 274: 227-236.

Jia, T. H. and L. H. Yang. 1996. The effect of Hippophae on soil fertility and the analysis of Nitrogen fixation by nodules. Chin. J. Soil Sci. 27: 268-269.

John, N. M. and Q. Wang. 2015. Seasonal response of Chlorophyll a/b ratio to stress in a typical desert species: Haloxylon ammodendron. Arid Land Res. Manage. 29: 321-334.

Kaur, H., R. Kaur, S. Kaur, I. T. Baldwin and Inderjit. 2009. Taking ecological function seriously: Soil microbial communities can obviate allelopathic effects of released metabolites. PLoS One. 4: e4700.

Li, J., Z. W. Liu, N. Tian and T. F. Shi. 2013b. Allelopathic effects of plantation defoliations on Medicago sativa in the Loess Plateau. Acta Agrestia Sin. 21: 92-99.

Li, Y. Q., T. X. Hu, F. M. Zeng, H. Chen and X. H. Wu. 2013a. Effects of Eucalyptus grandis leaf litter decomposition on the growth and resistance physiology traits of Eremochloa ophiuroides. J Plant Stud. 2: 158-165.

Liu, X. Y. and D. H. Zeng. 2007b. Research advances in interspecific interactions in agroforestry system. Chin. J. Ecol. 26: 1464-1470.

Liu, Z. W., E. J. Duan and G. Fu. 2007a. Anew concept: Soil polarization in planted pure forest. Acta Pedol. Sin. 44: 1119-1126.

Lovett, V. and J. Levitt. 1985. Alkaloids, antagonisms and allelopathy. Biol. Agric. Hortic. 2: 289-301.

Lu, X., X. R. Zhou and M. X. Du. 2013. Effects of Amorpha fruticosa on soil physical composition and nutrient content. Pratacultural Sci. 30: 994-1001.

Ma, R. J., M. L.Wand and K. Zhao. 2006. Allelopathy of aqueous extract from Ligularia virgaurea, a dominant weed in psychrograssland, on pastrue plants. Chin. J. Appl. Ecol. 17: 845-850.

Meiners, S. J. 2014. Functional correlates of allelopathic potential in a successional plant community. Plant Ecol. 215: 661-672.

Parepa, M., U. Schaffner and O. Bossdorf. 2012. Sources and modes of action of invasive knot weed allelopathy: The effects of leaf litter and trained soil on the germination and growth of native plants. Neobiota. 13: 15-30.

Prati, D. and O. Bossdorf. 2004. Allelopathic inhibition of germination by Alliaria petiolata (Brassicaceae). Am. J. Bot. 2: 285-288.

Song, L., K. W. Pan and J. C. Wang. 2006. Review on action mechanism of effects of Allelochemicals on Seeds Germination. World Sci. Tech. R\&D. 28: 52-57.

Sun, Z. R., M. P. Zhai, R. P. He and R. Q. Wang. 2008. Effect of aqueous extracts on seed germination and seedling growth between Glycyrrhiza uralensis and Caragana microphylla. China 
J. Chin. Mater. Med. 33: 2459-2463.

Trouwborst, G., S. W. Hogewoning, J. Harbinson and W. V. leperen. 2011. Photosynthetic acclimation in relation to nitrogen allocation in cucumber leaves in response to changes in irradiance. Physiol. Plant. 142: 157-169.

Weidenhamer, J. D., M. Li, J. Allman, R. G. Bergosh and M. Posner. 2013. Evidence does not support a role for gallic acid in Phragmites australis invasion success. J. Chem. Ecol. 2: 323-332.

Xie, X. G., Y. Chen, Y. Q. Bu and C. C. Dai. 2014. A review of allelopathic researches on phenolic acids. Acta Ecol. Sin. 34: 6417-6428.

Yang, Q. H., W. H. Ye and F. L. Liao. 2005. Effect of allelochemicals on seed germination. Chin. J. Ecol. 24: 1459-1465.

Yuan, S. A., F. Guo and C. P. Tang. 2015. Allelopathic effects of the aqueous extracts of Hippophae rhamnoides L. subsp. Sinensis on the germination of its seeds. J. Arid Land Resour. Environ. 29: $116-121$.

Zhang, X. X., Z. W. Liu, N. Tian, N. T. Luc, B. C. Zhu and Y. H. Bing. 2015. Allelopathic effects of decomposed leaf litter from intercropped trees on rape. Turk. J. Agric. Forest. 39: 898-908. DOI: 10.3906/ tar-1406-88.

Zhang, Y., M. Gu, X. J. Xia, K. Shi, Y. H. Zhou and J. Q. Yu. 2010. Alleviation of autotoxin induced growth inhibition and respiration by sucrose in Cucumis sativus (L.). Allelopathy J. 25: 147-154.

Zhong, Z. K., H. M. Yang, Z. Z. Zhai, M. Shao and P. T. Gong. 2015. Caragana korshinskii biochar and its application in the degradation of soil restoration. Forest. Sci. Technol. 1: 19-22.

Zhou, X. and F. Wu. 2012. P-coumaric acid influenced cucumber rhizosphere soil microbial communities and the growth of Fusarium oxysporum f.sp. Cucumerinum owen. PLoS One. 7: e48288. 